\title{
Expression of Neural Cell Adhesion Molecule L1 in Human Lung Cancer Cell Lines
}

\author{
Masahiro Katayama ${ }^{1}$, Akihiko Iwamatsu ${ }^{2}$, Hiroshi Masutani ${ }^{1}$, Keizo Furuke ${ }^{1}$, Kazumasa Takeda ${ }^{1}$, \\ Hiromi Wada ${ }^{3}$, Tohru Masuda ${ }^{4}$, and Kazuhiro Ishii ${ }^{*}$ \\ ${ }^{1}$ Institute for Virus Research, and ${ }^{3}$ Chest Disease Research Institute, Kyoto University, Shogoin Kawahara-cho, \\ Sakyo-ku, Kyoto 606-01, Japan; ${ }^{2}$ Central Laboratories for Key Technology, Kirin Brewery, Fukuura, Kana- \\ zawa-ku, Yokohama 236, Japan; ${ }^{4}$ Department of Immunobiology, Faculty of Medicine, Kyoto University, \\ Yoshida Konoe-cho, Sakyo-ku, Kyoto 606. Japan
}

Key words: cell adhesion molecule L1/carcinoma/lung cancer/neuroblastoma/monoclonal antibody

\begin{abstract}
To investigate neuron-specific antigens, hybridoma cells were produced between mouse spleen cells immunized with human neuroblastoma cells (IMR-32) and mouse myeloma cells. 247 hybridoma clones were harvested and one of them was further cultured for recloning. Eventually, one hybridoma clone was obtained and its antibody was designated $\mathrm{N}$-A8. The characteristics of this antibody were determined by immunostaining and flow cytometry. First, the antibody recognized the surface antigens of IMR-32 cells. Second, unexpectedly, $\mathrm{N}$-A8 was reactive not only with human neuroblastoma cell lines but also with human lung cancer cell lines. As analyzed by immunoprecipitation method and SDS-PAGE, the molecular size of the antigen recognized by $\mathrm{N}$-A8 was $210 \mathrm{kDa}$. The antigen was then purified by affinity chromatography and identified as neural adhesion molecule $\mathrm{L1}$ by amino acid sequence analysis. By the present investigation, it was clearly demonstrated that $\mathrm{L1}$ is expressed in human lung cancer cells.
\end{abstract}

Neuroblastoma is a solid malignant tumor of childhood which is of neural crest origin. In vitro established cell lines of neuroblastomas have been available as good models for studies of cell differentiation because their cells can be induced to differentiate to neuronal cells (see ref. 9), Schwann cells (28) and melanocytes (20) by treatment with various reagents. Moreover, many monoclonal antibodies against membrane antigens of these cells have been produced for studies of cell differentiation, tumor diagnosis and therapy $(2,3,14,16,26,30)$.

To investigate neuron-specific antigens, we have made hybridomas that produce monoclonal antibodies against human neuroblastoma cells IMR-32. One monoclonal antibody was obtained and designated N-A8 (11). This antibody was further investigated in detail, and two interesting properties were detected. First, NA8 can recognize specifically the extracellular domains of human neural cell adhesion molecule L1. Second, unexpectedly, N-A8 was reactive not only to human neuroblastoma cell lines but also to human lung cancer cell lines and other human carcinoma cell lines. N-A8 will find application in molecular biological and diagnostic

\footnotetext{
* To whom correspondence should be addressed.

Fax: 81-75-761-5626

E-mail: kishii@virus.kyoto-u.ac.jp
}

studies of human lung cancer cells.

\section{MATERIALS AND METHODS}

Cell lines. For immunization of BALB/c mice, human neuroblastoma cells IMR-32 (ATCC CCL-127) were used. For specification of monoclonal antibodies, the following human cells lines were used: IMR-32, LA-N2 (Riken Cell Bank: RCB 484), NB-1, NB-9 (RCB 477), RT-BM-1, SK-N-MC (ATCC HTB-10), SK-N-SH (RCB 426) (these are neuroblastoma cells), BIM (hybrid cells of IMR-32 $\times$ B3T) (9), Y-79 (retinoblastoma) (RCB 427), 284 (skin fibroblast), HT1080 (fibrosarcoma) (ATCC CCL-121), U251-mg (astrocytoma), GI$1 \mathrm{~K}$ (gliosarcoma), FL (amnion), HeLa (cervical carcinoma), HSC-1 (squamous cell carcinoma) (17), KB (oral carcinoma), A549 (lung alveolar carcinoma) (ATCC CCL185), PC-14 (lung adenocarcinoma) (RCB0446), Lu-139 (small cell lung carcinoma) (RCB 0469), SBC-1 (small cell lung carcinomas) (JCRB 816), HMOS-3 (melanoma), Daudi (Burkitt's lymphoma), U937 (monocytic lymphoma), K562 (chronic myelocytic leukemia) and MOLT-4 (T cell leukemia). Other mammalian cell lines were also used, including C1300 (Neuro-2a) (mouse neuroblastoma) (ATCC CCL-131), B3T (rat neuroblastoma) (8), PC12 (rat adrenal pheochromocytoma) (ATCC CRL1721), B16 (mouse melanoma), VR-2g (mouse glial cells) (10), C6 (rat glial tumor cells), CHO-K1 (Chinese hamster ovary), 
and HaK (Syrian hamster kidney) (ATCC CCL-15). For cell fusion, P3X-63Ag8-653 cells (a gift of Dr. M. Ueda) were used. Cells were cultured in Dulbecco-Vogt's modification of Eagle MEM or RPMI 1640 supplemented with 10\% fetal calf serum.

Immunization of mice. $\mathrm{BALB} / \mathrm{c}$ mice were immunized peritoneally with IMR-32 cells $\left(2 \times 10^{7}\right.$ cells/mouse) suspended in Freund's complete adjuvant (1:1 in volume). Fourteen days later, mice were subject to a second immunization with IMR32 cells suspended in Freund's incomplete adjuvant. Then, sixteen days after the second immunization, mice received a booster of IMR-32 cells without the adjuvant. Three days later, spleens were excised from immunized mice.

Cell fusion. For cell dissociation, spleens were cut vertically into two pieces and pressed with tweezers. Cell yield was 3 $\times 10^{8}$ cells per spleen. Spleen cells were mixed with mouse myeloma cells P3X-63Ag8-653 (10:1 in cell number) and fused by the treatment with polyethylene glycol 4000 (Merck) (50\% solution). After washing with serum-free medium, cells were inoculated at $1.7 \times 10^{5}$ cells per well in 96-well plates. The growth medium was RPMI 1640 supplemented with $10 \%$ fetal calf serum. One day later, the medium was exchanged to the HAT-medium (100 $\mu \mathrm{M}$ hypoxanthine, $0.4 \mu \mathrm{M}$ aminopterin and $16 \mu \mathrm{M}$ thymidine). Eight days later, the culture fluids were harvested for screening monoclonal antibodies, and colonies were subcultured.

Immunostaining. For screening of monoclonal antibodies (MAb) produced by hybridomas, IMR-32 cells were dissociated in phosphate-buffered saline (PBS), and after washing, the cell suspension was dropped onto multiwell-glass slides (Heavy Teflon Coating) (Wheaton, IL). Cells were then airdried and fixed in acetone at $-20^{\circ} \mathrm{C}$ for $15 \mathrm{~min}$. For immunostaining, cells were washed with PBS, $2 \%$ FCS/PBS, and then treated with the culture fluids of hybridomas at room temperature for $40 \mathrm{~min}$. After washing with PBS, cells were treated with FITC-labeled rabbit antibodies against mouse immunoglobulins (DAKO) for $30 \mathrm{~min}$, and washed with PBS. Immunostained cells were observed under a fluorescent microscope (Nikon). For determination of intracellular localization of cellular antigens recognized by monoclonal antibodies, cells were cultured on glass coverslips, air-dried, and fixed in acetone at $-20^{\circ} \mathrm{C}$ for $15 \mathrm{~min}$. Cells were immunostained as described above. For flow cytometry, cells were dissociated in PBS after washing three times. Cells were suspended in PBS containing $1 \%$ FCS, immunostained without fixation as described above, and analyzed by a flow cytometer (Cytron, Ortho Diagnostic Systems).

Typing of immunoglobulins. Immunoglobulin classes of monoclonal antibodies produced by hybridoma cells were determined by the Ouchterlony's immunodiffusion method. Briefly, $1 \%$ agarose gels were made in $60-\mathrm{mm}$ plastic dishes, punched for holes of appropriate diameters, in which the antibodies against various classes of mouse immunoglobulins (Miles) and the culture fluids of hybridoma cells were put. After incubation overnight at room temperature, the immuno- diffusion bands were read.

Immunoprecipitation. Cells were cultured to subconfluent state in a growth medium, and after the medium was exchanged to the methionine-free Dulbecco's modified MEM medium containing $5 \%$ dialyzed FCS, preincubated at $37^{\circ} \mathrm{C}$ for $30 \mathrm{~min}$. Cells were then incubated with the $\left.{ }^{[35} \mathrm{S}\right]-$ methionine/cysteine $(0.06 \mathrm{mCi} / \mathrm{ml})$ (Translabel: $\mathrm{ICN})$ at $37^{\circ} \mathrm{C}$ for 4 h. After washing in PBS, cells were lysed with a lysis buffer (10 mM Tris- $\mathrm{HCl}, 150 \mathrm{mM} \mathrm{NaCl}, 0.5 \%$ NP-40 (Nonidet P40), $1 \mathrm{mM}$ PMSF (phenyl methyl sulfony fluoride), $0.1 \mathrm{TIU}$ $/ \mathrm{ml}$ aprotinin, $0.02 \% \mathrm{NaN}_{3}, \mathrm{pH}$ 7.4) (32). Cell lysates were pretreated twice with irrelevant IgG cross-linked to protein Asepharose CL-4B (Pharmacia) to remove non-specific antigens. After centrifugation, the supernatants were incubated with culture fluids of hybridoma cells (sources of MAbs) at $4^{\circ} \mathrm{C}$ for $60 \mathrm{~min}$, and after the addition of rec-protein G-sepharose 4B (Zymed), further incubated for $60 \mathrm{~min}$. The immunocomplexes were extensively washed with the lysis buffer, and boiled in a sodium dodecylsulfate (SDS)-sample buffer (62.5 mM Tris- $\mathrm{HCl}, 10 \%$ glycerol, 2.3\% SDS, 5\% 2-mercaptoethanol, $0.0025 \%$ bromophenol blue, $\mathrm{pH} \mathrm{7.6)}$ at $100^{\circ} \mathrm{C}$ for $2 \mathrm{~min}$. The samples were analyzed by SDS/PAGE (polyacrylamide gel electrophoresis) (Multigel 2/15: Daiichi Pure Chem.) according to the method of Laemmli (19). The molecular markers were purchased from Amersham (Rainbow Protein Molecular Weight Markers: ${ }^{14} \mathrm{C}$-labeled). The gels were dried and measured by autoradiography with an imaging analyzer (BAS 2000, FUJIX).

Affinity chromatography. To purify the membrane antigens of IMR-32 cells, affinity chromatography was performed. For preparation of activated sepharose CL-4B, the sepharose was treated with cyanogen bromide at $\mathrm{pH} 11$ according to the method of Cuatrecasas et al. (4). For purification of monoclonal antibody $\mathrm{N}-\mathrm{A} 8$, the ascites fluid containing the antibody was applied to a Protein A column in a Tris buffer ( $\mathrm{pH}$ 8.0) and eluted by a glycine buffer $(\mathrm{pH} 2.6)$. The eluate was adjusted to $\mathrm{pH} 7.0$, dialysed in carbonate buffer ( $\mathrm{pH} 9.0$ ) overnight, and then concentrated by Molcut II (Millipore). For coupling of purified antibodies to activated Sepharose, they were mixed in carbonate buffer and stirred at $4^{\circ} \mathrm{C}$ overnight. After washing in carbonate buffer, the unreacted ligands were blocked by treatment with glycine in a carbonate buffer. For preparation of the membrane fraction of IMR-32 cells, the cells were harvested from the culture dishes by trituration in calcium-/magnesium-free PBS, suspended in a hypotonic solution, and processed by freezing/thawing. The broken cell suspension was centrifuged at $10,000 \times \mathrm{g}$ at $4^{\circ} \mathrm{C}$ for $20 \mathrm{~min}$, and the pellet was then solubilized by a lysis buffer, followed by centrifugation. The lysate thus obtained was applied to the antibody-coupled Sepharose column in a Tris buffer $(\mathrm{pH} \mathrm{8.0)}$, and after washing with a Tris buffer, eluted with a glycine buffer ( $\mathrm{pH}$ 2.6). The eluate containing the membrane antigens was adjusted to $\mathrm{pH} 7.0$, and concentrated by vacuum centrifugation.

Determination of amino acid sequence. The purified anti- 
gens were mixed with a sample buffer containing 2-mercaptoethanol, and applied to SDS-PAGE (19). The gel was transferred to Problott ${ }^{\mathrm{TM}}$ by electroblotting. The protein band transferred on a polyvinylidene difluoride membrane was reduced and s-carboxymethylated, followed by in situ digestion with Achromobacter protease I (12). The digested peptides were subjected to reverse phase HPLC using a Wakosil-II AR C18 $300 \mathrm{~A}(2.0 \times 150 \mathrm{~mm}$, Wako Pure Chemical $)$ column. The fractionated peptides were collected manually by monitoring the absorbance at $205 \mathrm{~nm}$. Amino acid sequencing was performed with a gas-phase sequencer (model PPSQ-10, Shimadzu).

\section{RESULTS}

Screening of hybridomas. 247 hybridoma clones were harvested and examined for specific reactiveness of their antibodies to IMR-32 cells by immunostaining. A total of 34 clones were selected and further tested for detection of the antibodies recognizing the surface antigens of IMR-32 cells by flow cytometry. Thus, one hybridoma clone was selected and named \#72. For recloning, this clone was further cultured in multiwell plates, and 56 colonies were isolated. These clones were examined by flow cytometry. Thus, one hybridoma clone was isolated and its antibody was designated N-A8 (11).

Specificity of monoclonal antibodies. The fact that the antibody N-A8 actually recognized the surface antigens of IMR-32 cells was confirmed by immunostaining of cells cultured on coverslips (Fig. 1a) and by flow cytometry with suspended viable cells treated with the antibody (Fig. 2b and Table I). Interestingly, KB cells also exhibited the similar staining properties to those of IMR-32 cells (Fig. $1 \mathrm{~b}$ and $2 \mathrm{~d}$ ).

To determine species- and cell-specificity of the antibody, various cell lines were examined by flow cytometry. Two interesting results were obtained. First, N-A8
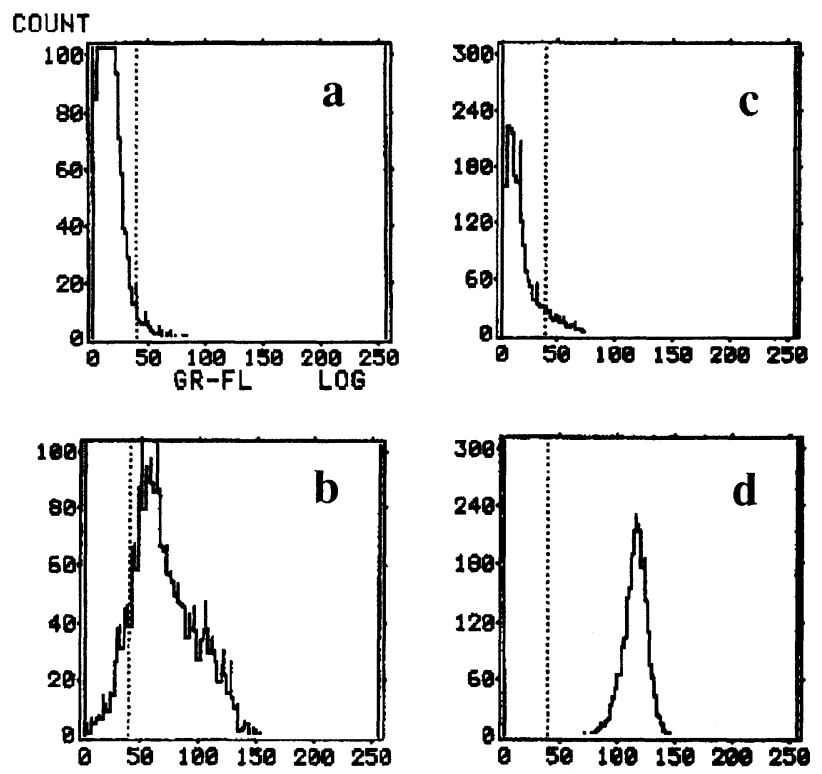

Fig. 2. Distribution of the cells reactive with monoclonal antibodies. Suspended viable cells were treated with control supernatant $(a, c)$ or hybridoma supernatants $(\mathrm{N}-\mathrm{A} 8)(\mathrm{b}, \mathrm{d})$, and stained with FITC-labeled rabbit anti-mouse Ig. The stained cells were measured by flow cytometry. (a, b) IMR-32 cells, (c, d) KB cells.

was human cell-specific. Other mammalian cells were not reactive to the antibody (Table I). Second, N-A8 was reactive not only to human neuroblastoma cell lines and a retinoblastoma cell line, but also to human carcinoma cell lines and human lung cancer cell lines (Table I). Other types of human cells including melanoma, fibrosarcoma, glioma and leukemias were negative in reactiveness to N-A8 (Table I).

Determination of immunoglobulin classes. The heavy-chain class of N-A8 antibody was tested by an im-
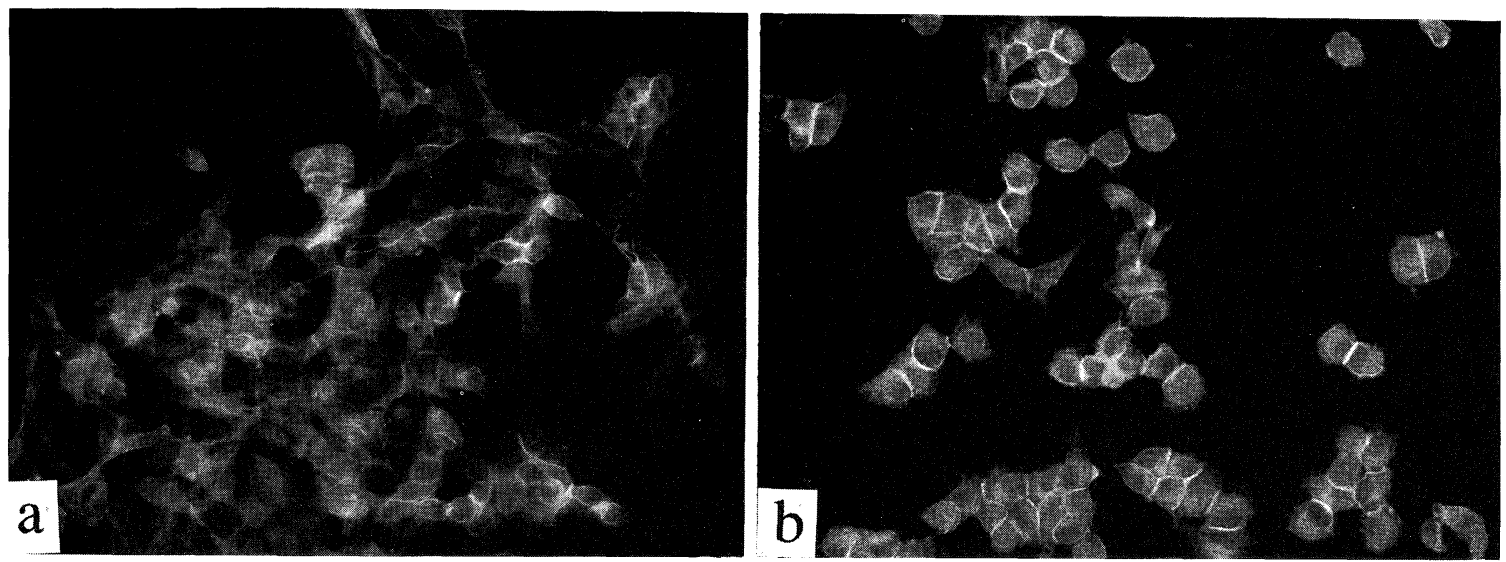

Fig. 1. Staining patterns of IMR-32 cells treated with monoclonal antibodies. Cells were cultured on glass coverslips, fixed in acetone, and then incubated with N-A8, followed by treatment with FITC-labeled rabbit anti-mouse Ig. (a) IMR-32 cells, (b) KB cells. 
Table I. Reactiveness of Various Cell Lines to Monoclonal Antibodies.

\begin{tabular}{|c|c|c|c|}
\hline Cells & $\mathrm{N}-\mathrm{A} 8$ & Cells & N-A8 \\
\hline Human neuroblastomas & & Human immunocytes & \\
\hline IMR-32 & H & Daudi & - \\
\hline LA-N2 & H & K562 & - \\
\hline NB-1 & H & MOLT-4 & - \\
\hline NB-9 & H & U937 & - \\
\hline RT-BM-1 & H & Human fibroblasts & \\
\hline SK-N-MC & H & 284 & - \\
\hline SK-N-SH & H & HT1080 & - \\
\hline Human retinoblastomas & & Hybrids of IMR-32 $\times \mathrm{B} 3 \mathrm{~T}$ & \\
\hline Y-79 & m & BIM & H \\
\hline Human glial cells & & Other mammalian cells & \\
\hline $\mathrm{U} 251$ & $+1-$ & B3T & - \\
\hline GI-1K & - & $\mathrm{C} 1300$ & - \\
\hline Human melanomas & & $\mathrm{PC} 12$ & - \\
\hline HMOS-3 & - & C6 & - \\
\hline Human epithelial cells & & VR-2g & - \\
\hline FL & H & B16 & - \\
\hline $\mathrm{HeLa}$ & H & CHO-K1 & - \\
\hline HSC-1 & + & HAK & - \\
\hline KB & H & & \\
\hline \multicolumn{4}{|l|}{ Human lung cancers } \\
\hline A549 & + & & \\
\hline Lu139 & $+1-$ & & \\
\hline PC-14 & H & & \\
\hline SBC-1 & $H$ & & \\
\hline
\end{tabular}

Viable cells were suspended in PBS, and stained with monoclonal antibodies N-A8, followed with FITClabeled rabbit anti-mouse Ig. The staining levels were then determined by flow cytometry. The percentages of the positively stained cells were expressed as follows: (-) 0 to $10 \%,( \pm) 10$ to $20 \%,(+) 20$ to $50 \%$, (+) 50 to $80 \%$, (H) 80 to $100 \%$. nd, not done.

munodiffusion method. N-A8 was of $\mathrm{IgG}_{1}$ class (data not shown).

Characterization of cellular antigens recognized by antibodies. Molecular sizes of the cell antigens recognized by $\mathrm{N}-\mathrm{A} 8$ were determined by an immunoprecipitation method and SDS/PAGE analysis. When the lysates of IMR-32 cells were immunoprecipitated with NA8 and then applied to SDS-PAGE, one dense band corresponding to $210 \mathrm{kDa}$ was detected (Fig. 3, lane c). The $210 \mathrm{kDa}$ molecule was also detected by Western blot analysis (data not shown). As shown in Fig. 3 (lane a), a similar molecule $(220 \mathrm{kDa})$ was also detected in the lysates of KB cells, as expected from the immunostaining results (Table I). It should be noted that N-A8 is available for three experimental techniques i.e., immunostaining, Western blotting, and immunoprecipitation method.

Purification and determination of amino acid sequence of $210 \mathrm{kDa}$ molecules. For purification of $\mathrm{N}$-A8-recognizing antigens, the membrane fraction of IMR-32 cells was prepared by a freeze-thaw method, and solubilized in a lysis buffer. The lysate was applied to affinity chromatography and the eluate was collected. When the eluate was applied to SDS-PAGE, one band was detected in a gel. This band was used for amino acid sequence analysis.

The antigenic protein thus obtained was digested with Achromobacter protease I as described in "Materials and Methods", and applied to reverse phase HPLC. Three peptide fragments (AP2, AP3, and AP6) were obtained, and then their amino acid sequences were determined. Interestingly, the amino acid sequences were completely identical to those of human cell adhesion molecule L1 (accession number A41060) (Fig. 4): AP-3 corresponds to the 176-180 residues of L1; AP-2 to the 516-526 ones; AP-6 to the 695-708 ones, respectively. Based on these results, we concluded that N-A8 can recognize the extracellular domains of human L1.

\section{DISCUSSION}

In the present investigation, a monoclonal antibody 


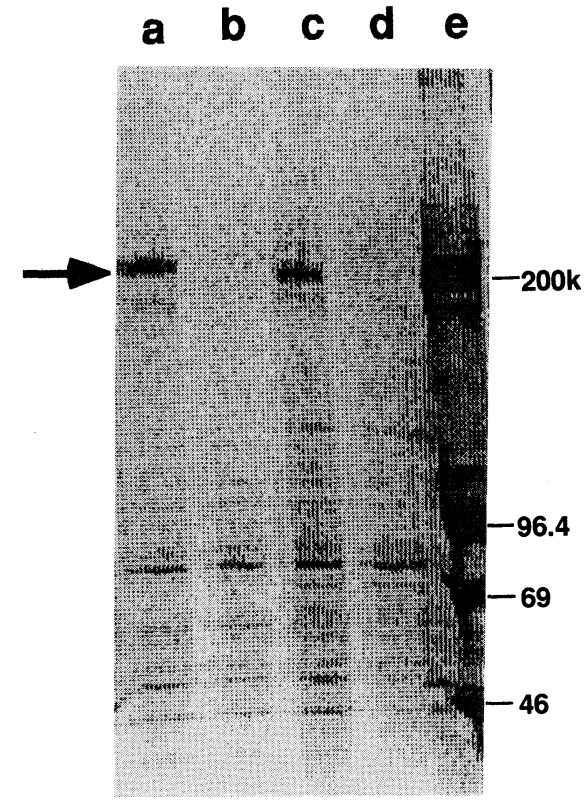

Fig. 3. SDS-polyacrylamide gel electrophoresis of cellular antigens immunoprecipitated with the monoclonal antibody N-A8. The lysates of KB $(a, b)$ and IMR-32 (c, d) cells were reacted with N-A8 $(a, c)$ or control medium (b, d), and treated with protein G-sepharose. The immunocomplexes were analyzed by SDS-PAGE. The arrow indicates the cellular antigen recognized by N-A8. (e) the marker molecules.

N-A8 was characterized, and its recognizing antigen was identified as human neural cell adhesion molecule L1. Surprisingly, N-A8 was reactive with human lung cancer cell lines and other human carcinoma cell lines though L1 is well known to be specifically expressed in neurons and Schwann cells $(5,23,25)$. It is of interest to determine how $\mathrm{L} 1$ gene expression is regulated in those epithelial cell lines. In regard to this issue, there is a report that L1 was detected in proliferating epithelial pro-

\section{Human L1

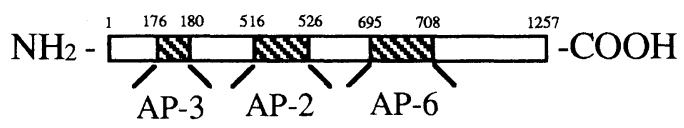

\author{
Human L1: ILHIK (176-180) \\ AP-3: ILHIK \\ Human L1: DATQITQGPRS (516-526) \\ AP-2: DATQITQGPRS \\ Human L1: YGPGEPSPVSETVV (695-708) \\ AP-6: YGPGEPSPVSEXVV
}

Fig. 4. Amino acid sequences of three digested peptide fragments (AP-2, AP-3 and AP-6) of N-A8-recognizing antigenic proteins. Amino acid sequences were determined by a gas-phase sequencer. $X$ : undefined amino acid. genitor cells of adult mouse intestine (31), suggesting that epithelial cells are regulated to express L1 during development. Taken together, it is highly probable that epithelial tumor cells maintain the developmental property to express $\mathrm{L} 1$. The investigation on the expression patterns of L1 in human lung cancers will be useful for their diagnosis and therapy.

$\mathrm{N}-\mathrm{A} 8$ exhibited unique properties. First, irrespective of a fact that human L1 is approximately $90 \%$ homologous to mouse L1 (7), N-A8 was not reactive to mouse neuroblastoma $\mathrm{C} 1300$ cells which is known to express murine $\mathrm{L} 1$ antigens (25). This suggests that $\mathrm{N}-\mathrm{A} 8$ is highly specific for human cells. Second, N-A8 was reactive to all human neuroblastoma cell lines so far tested, suggesting that L1 can be a good marker for neural cells in development. Although neuroblastomas are known to exhibit antigenic heterogeneity (27) and diversity in differentiation potency $(18,20,21,28,33), \mathrm{N}-\mathrm{A} 8$ will find great application in studies on the differentiation of neuroblastoma cells by using together with other antibodies such as anti-intermediate filaments $(6,24)$.

The present experimental results provide a clue for interpretation of somewhat complicated information reported by many investigations $(1,13,15,22,27,29)$. Many monoclonal antibodies directed to human neuroblastoma cells including IMR-32 cells have been reported, and some of them show similar properties to those of our antibody $(1,15,27)$. However, subtle differences are present between them. For example, the monoclonal antibody UJ 127:11 (15) is known to recognize a cellular antigen of $220-240 \mathrm{kDa}$ and to be reactive to human neuroblastoma cells and retinoblastoma cells. But this antibody is also reactive to melanoma cells, which is different from the reactiveness of our antibody (N-A8). In consideration of its molecular size, it is highly likely that UJ 127:11 recognizes human L1. If this is the case, the recognized sites of L1 antigen may be different between the antibodies N-A8 and UJ 127:11.

Acknowledgments. We are grateful to Drs. M. Ueda and M. Iwashiro for their assistance with immunological experiments and helpful discussion, to Dr. M. Kitano for HMOS-3 cells, to Dr. J. Minowada for MOLT-4 cells, to Dr. S. Miyatake for U251-mg and GI-1K cells, to Dr. T. Nakanishi for PC12 cells, to Dr. Y. Sachi for HSC-1 cells, to Dr. T. Sakai for NB-1 cells, to Dr. H. Shida for FL cells, and to Dr. T. Sugimoto for RT-BM-1 cells.

\section{REFERENCES}

1. Allan, P.M., Garson, J.A., Harper, E.I., Asser, U., Coakham, H.B., Brownell, B., and Kemshead, J.T. 1983. Biological characterization and clinical applications of a monoclonal antibody recognizing an antigen restricted to neuroectodermal tissues. Int. J. Cancer, 31: 591-598.

2. Amstutz, H., Rytz, Ch., Novak-Hofer, I., Spycher, M., Schubiger, P.A., Blaser, K., and Morgenthaler, J.-J. 
1993. Production and characterization of a mouse/human chimeric antibody directed against human neuroblastoma. Int. J. Cancer, 53: 147-152.

3. Coakham, H.B., Garson, J.A., Allan, P.M., Harper, E.I., Brownell, B., KemsheAd, J.T., and LANE, E.B. 1985. Immunohistological diagnosis of central nervous system tumours using a monoclonal antibody panel. J. Clin. Pathol., 38: 165-173.

4. Cuatrecasas, P., Wilcheck, M., and Anfinsen, C.B. 1968. Selective enzyme purification by affinity chromatography. Proc. Natl. Acad. Sci. USA, 61: 636-643.

5. Edelman, G.M. and Crossin, K.L. 1991. Cell adhesion molecules: Implications for a molecular histology. Annu. Rev. Biochem., 60: 155-190.

6. Franke, W.W., Schmid, E., Winter, S., Osborn, M., and WEBER, K. 1979. Widespread occurrence of intermediate-sized filaments of the vimentin-type in cultured cells from diverse vertebrates. Exp. Cell Res., 123: 25-46.

7. Hlavin, M.L. and Lemmon, V. 1991. Molecular structure and functional testing of human L1 CAM: An interspecies comparison. Genomics, 11: 416-423.

8. IsHII, K. 1990. Isolation of thymidine-requiring variants from rat nerve-like cells. Cell Struct. Funct., 15: 93-97.

9. IshiI, K., Adachi, Y., HatanaKa, M., SaKamoto, H., and FuruYama, J. 1990. Spontaneous and cAMP-dependent induction of a resting phase and neurite formation in cell hybrids between human neuroblastoma cells and thymidine auxotrophs of rat nerve-like cells. J. Cell. Physiol., 143: 569-576.

10. Ishit, K., INOUE, H., HaKURA, A., ARAKI, W., and Masuda, T. 1992. Immortalization of fetal mouse brain glial cells by human papillomavirus type 16 E7 genes. Cell Struct. Funct., 17: 197-202.

11. Ishit, K., Katayama, M., Masutani, H., Furuke, K., Takeda, K., and MASUdA, T. 1993. Monoclonal antibodies reactive with human neuroblastoma cells. Cell Struct. Funct., 18: 629.

12. Iwamatsu, A. 1992. S-carboxymethylation of proteins transferred onto polyvinylidene difuloride membranes followed by in situ protease digestion and amino acid microsequencing. Electrophoresis, 13: 142-147.

13. Jennings, M.T., Jennings, V.D.L., Asadourian, L.L.H., Rosenblum, M., Albino, A.P., Cairncross, J.G., and Old, L.J. 1989. Five novel cell surface antigens of CNS neoplasms. J. Neurol. Sci., 89: 63-78.

14. Kemshead, J.T., Walsh, F., Pritchard, J., and Greaves, M. 1981. Monoclonal antibody to ganglioside GQ discriminates between haemopoietic cells and infiltrating neuroblastoma tumour cells in bone marrow. Int. J. Cancer, 27: 447-452.

15. Kemshead, J.T., Fritschy, J., Garson, J.A., Allan, P., CoAKham, H., Brown, S., and Asser, U. 1983. Monoclonal antibody UJ 127:11 detects a 220,000-240,000 kdal. glycoprotein present on a sub-set of neuroectodermally derived cells. Int. J. Cancer, 31: 187-195.

16. Kennett, R.H. and Gilbert, F. 1979. Hybrid myelomas producing antibodies against a human neuroblastoma antigen present on fetal brain. Science, 203: 1120-1121.

17. Kondo, S. and Aso, K. 1981. Establishment of a cell line of human skin squamous cell carcinoma in vitro. British J. Dermatol., 105: 125-132.

18. Kyritsis, A.P., Tsokos, M., Triche, T.J., and Chader, G.J. 1984. Retinoblastoma - origin from a primitive neuroectodermal cell? Nature, 307: 471-473.

19. LAEMmLI, U.K. 1970. Cleavage of structural proteins during the assembly of the head of bacteriophage T4. Nature, 227: 680-685.
20. Maeda, K., Feyles, V., McGarry, R.C., and Jerry, L.M. 1990. Melanocytic differentiation of human neuroblastoma: Expression of a human melanosome-associated antigen. $J$. Invest. Dermatol., 95: 665-670.

21. Matsumoto, M., Akiyama, T., Miyatake, S., Oda, Y., KiKUCI, H., HANAOKa, M., and NAMBa, Y. 1989. Expression of proto-oncogene products during drug-induced differentiation of a neuroblastoma cell line SK-N-DZ. Acta Neuropathol., 79: 217-221.

22. Mattes, M.J., Cordon-Cardo, C., Lewis, J.L., Jr., Old, L.J., and LlOYD, K.O. 1984. Cell surface antigens of human ovarian and endometrial carcinoma defined by mouse monoclonal antibodies. Proc. Natl. Acad. Sci. USA, 81: 568-572.

23. Moos, M., Tacke, R., Scherer, H., Teplow, D., Frueh, K., and SCHACHNER, M. 1988. Neural adhesion molecule L1 as a member of immunoglobulin superfamily with binding domains similar to fibronectin. Nature, 334: 701-703.

24. PARYSeK, L.M., Chisholm, R.L., Ley, C.A., and Goldman, R.D. 1988. A type III intermediate filament gene is expressed in mature neurons. Neuron, 1: 395-401.

25. RAthJen, F.G. and SChAChNER, M. 1984. Immunocytological and biochemical characterization of a new neuronal cell surface component ( $\mathrm{L} 1$ antigen) which is involved in cell adhesion. EMBO J., 3: 1-10.

26. Rettig, W.J., Spengler, B.A., Chesa, P.G., Old, L.J., and BIEDLER, J.L. 1987. Coordinate changes in neuronal phenotype and surface antigen expression in human neuroblastoma cell variants. Cancer Res., 47: 1383-1389.

27. Schoenmann, S.M., Iyer, J., Laeng, H., Gerber, H.A., KAESER, H., and Blaser, K. 1986. Production and characterization of monoclonal antibodies against human neuroblastoma. Int. J. Cancer, 37: 255-262.

28. Sugimoto, T., Kato, T., Sawada, T., HoriI, Y., Kemshead, J.T., Hino, T., MoRioka, H., and Hosol, H. 1988. Schwannian cell differentiation of human neuroblastoma cell lines in vitro induced by bromodeoxyuridine. Cancer Res., 48: 2531-2537.

29. Takahashi, T., Ueda, R., Song, X., Nishida, K., Shinzato, M., Namikawa, R., Ariyoshi, Y., Ota, K., Kato, K., Nagatsu, T., Imaizumi, M., Abe, T., and Takahashi, T. 1986. Two novel cell surface antigens on small cell lung carcinoma defined by mouse monoclonal antibodies NE-25 and PE-35. Cancer Res., 46: 4770-4775.

30. Thomas, J.O., Nijuar, J., Turley, H., Micklem, K., and GATTER, K.C. 1991. NB84: a new monoclonal antibody for the recognition of neuroblastoma in routinely processed material. J. Pathol., 163: 69-75.

31. Thor, G., Probstmeier, R., and Schachner, M. 1987. Characterization of the cell adhesion molecules L1, N-CAM and J1 in the mouse intestine. EMBO J., 6: 2581-2586.

32. Yamauchi, A., Masutani, H., Tagaya, Y., Wakasugi, N., Mitui, A., Nakamura, H., Inamoto, T., Ozawa, K., and YodoI, J. 1992. Lymphocyte transformation and thiol compounds; the role of $\mathrm{ADF} /$ thioredoxin as an endogenous reducing agent. Mol. Immunol., 29: 263-270.

33. ZAGON, I.S. and Schengrund, C.-L. 1978. Neuronal and non-neuronal properties of neuroblastoma cells. Exp. Cell Res., 114: $159-165$.

(Received for publication, March 27, 1997 and in revised form, June 23, 1997) 